\title{
Web-Based Approach to Calculations of Analog Circuits Characteristics
}

\author{
A.A. Lyalinsky \\ Institute for Design Problems in Microelectronics of Russian Academy of Sciences, \\ Moscow, ippm@ippm.ru
}

\begin{abstract}
A web-based system of analog circuit characterization (named ARS) is considered. It is considered the modes of setting input information, set of characterization procedures and modes of visualization of results. This developed system significantly reduce time of analog circuit design due to the reduced time for preparation of its simulation and increasing the reliability of the project due to performing estimation of circuit in its robustness area.

Keywords - cloud computing, circuit simulation system, information system, analog circuitry, circuit optimization, circuit optimization, web access, website.
\end{abstract}

\section{INTRODUCTION}

Under characterization of circuits it is understood a process of automatic calculation of circuit characteristics in a detailed space of environment parameters, which include: temperature, the power voltage, values of the output load and parameters of input signal. The data obtained as a result of this process allow us to construct a macromodel of a characterized circuit, using which one can further perform calculations at one of the modeling levels, more faster than the classical circuit spicesimulation.

Typically characterization is a calculation of hundreds or thousands of variants of impacts on the circuit and requires a lot of time and computer resources. Nevertheless, it has become widespread, especially at creating libraries of macromodels of digital cells [1]. The reason is the standard form of the logical signals and, as a result, the unified blocks of processing of input and output information of the cell. It allows to build rather accurate and high-speed macromodels of digital cells [2, 3, 9-11], having the uniform model structure: standard input-output blocks and between them a block of forming logic function.

In contrast to digital circuits, characterization of analog circuits is less common due to the lack of generally accepted typization of input and output signals, which is generated by a wide variety of variants for constructing input and output blocks of analog circuits. In [4] this topic was partially touched upon; no descriptions of any systems for characterization of analog circuits were found.

One can expand the concept of "characterization of circuit", understanding under it the calculation of not only variants for environmental impacts, but also and studying behavior with different variations of parameters of its constituent components (it is clear that only the variations of those components that significantly affect the most important characteristics of the circuit are of interest). Such extended interpretation allows us to estimate keeping performance of circuit at all deviations from nominal conditions, whether they are caused by environmental change or deviation of component parameters from initial values (e.g., due to aging or heating).

The considered system permits to perform characterization in an expanded form, evaluating both external influences and variations of its components. Further, in part II, a general description of system is given, in part III the set of the circuit calculated parameters is considered, in part IV - a description of the characterization procedures available in the system, in part $\mathrm{V}$ - a system for visualizing the results obtained, in part VI - features of the system design.

\section{CHARACTERIZATION OF ANALOG CIRCUIT}

Of the four mentioned above parameters, which are used to characterize digital circuits (ambient temperature, supply voltage, load value, input signal parameters), only two are left in the ARS - temperature and supply voltage. "Load magnitude" and "input signal parameters" are not considered due to the impossibility of their typing within reasonable limits for analog devices.

An operational amplifier was chosen as the starting type as the most "run-in" device and, probably, as most often used in the development of analog devices.

As mentioned above, the system implements two options for characterization - "classical" , which refers to the construction of a hyperplane for each user-specified circuit parameter in the space of parameters affecting the circuit - temperature and supply voltage, and extended, which refers to finding the dependencies of the circuit parameters on parameters its constituent elements. Further in the article we will use the following names: for classical - "Characterization on external impacts" and for extended - "Characterization on circuit components".

Now let consider briefly their input interfaces in ARS.

\section{A. Characterization on external impacts}

For temperature and supply voltage the user indicates the limits of change and the number of points (fig. 1). From the figure it can be seen that instead of a twodimensional characterization, you can order characterization by one parameter by ticking the 


\section{Set the parameters of characterization}

\section{VDD}

$\square$ do not use VDD-characterization

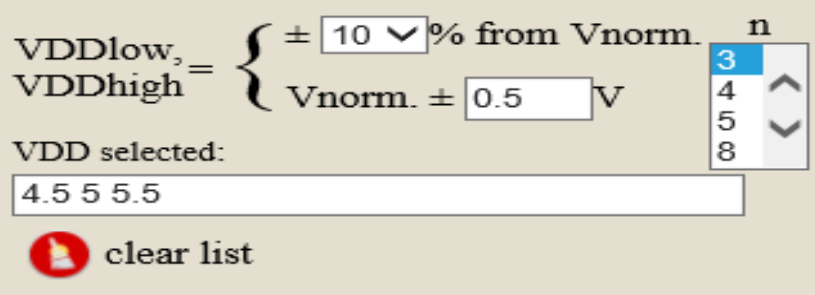

Temp

$\square$ do not use characterization on temperature

\begin{tabular}{|c|c|c|}
\hline Tlow, ${ }^{\circ} \mathrm{C}$ & Thome, ${ }^{\circ} \mathrm{C}$ & Thigh, ${ }^{\circ} \mathrm{C}$ \\
\hline$\checkmark \longdiv { - 4 0 }$ & $\checkmark \longdiv { 2 7 }$ & $\checkmark \longdiv { 1 2 5 }$ \\
\hline
\end{tabular}

temperature points selected:

$-4027125$

clear list

Fig. 1. Setting parameters for characterization by external influences

\section{B. Characterization on circuit components}

The following circuit components may be specified as varying parameters (fig. 2.):

- $\quad$ width and length of the MOS transistor,

- nominal of RCL-element,

- the value of an independent source of current or voltage (which is not the main source of power),
- transfer coefficient of linearly controlled current and voltage sources,

- global parameters described in the netlist operator ".PARAM".

Such a set of types of variable parameters makes it possible to investigate dependencies on any circuit elements.

\begin{tabular}{|c|c|c|c|c|c|}
\hline \multicolumn{6}{|c|}{ Transistors } \\
\hline list & elements & width, nm? & number of points & distance between points & connectivity of list \\
\hline new & & from: 10 & by def. & - linear $\bigcirc$ logarithmic & $\begin{array}{l}\square \text { change all elements } \\
\text { simultaneously }\end{array}$ \\
\hline invariable & M1 M2 M3 M4 & & & & \\
\hline \multicolumn{6}{|c|}{ Independent sources } \\
\hline list & elements & nominal ? & number of points & distance between points & connectivity of list \\
\hline new & & from: [ & $\frac{\text { by def. }}{2} \widehat{\vee}$ & - linear $\bigcirc$ logarithmic & $\begin{array}{l}\square \text { change all elements } \\
\text { simultaneously }\end{array}$ \\
\hline \multicolumn{6}{|c|}{\begin{tabular}{l|l} 
invariable & Ibias2 VDD Vin1 Vin 2 \\
\end{tabular}} \\
\hline \multicolumn{6}{|c|}{ Global parameters } \\
\hline list & elements & nominal ? & number of points & distance between points & connectivity of list \\
\hline new & & from: [ & 2 & - linear $\bigcirc$ logarithmic & $\begin{array}{l}\square \text { change all elements } \\
\text { simultaneously }\end{array}$ \\
\hline nvariable & w_m1m2 w_m3m41_m & $\mathrm{m} 3 \mathrm{~m} 4$ & & & \\
\hline
\end{tabular}

Fig. 2. Setting parameters for characterization by circuit components

\section{THE CALCULATED PARAMETERS}

If the set of variable parameters is practically independent of the type of circuit, then the set of calculated parameters on the contrary is strongly tied to this. The most important feature that determines whether a given parameter can be included in the list of indicators is the possibility of its automatic calculation from the simulation results. For the operational amplifier (OA), the following indicators were selected, calculated from the results of the frequency analysis and transient analysis (see also Fig. 3):

- low signal characteristics: o gain,

o cutoff frequency

o single amplification frequency

o the stability margin in phase

o power attenuation factor,

o common mode attenuation coefficient.

- $\quad$ Parameters of a large (time-varying) signal:

o the slew rate of the output voltage.

- $\quad$ Static mode options :

o current power. 
8. Вычисляемые показатели схемы (для класса схем: операционный усилитель):

Выберите показатели схемы, которые будут вычисляться в процессе моделирования схемы. Убедитесь, что предлагаемые параметры команд, по результатам выполнения которых будут вычислены выбранные показатели, вас удовлетворяют.

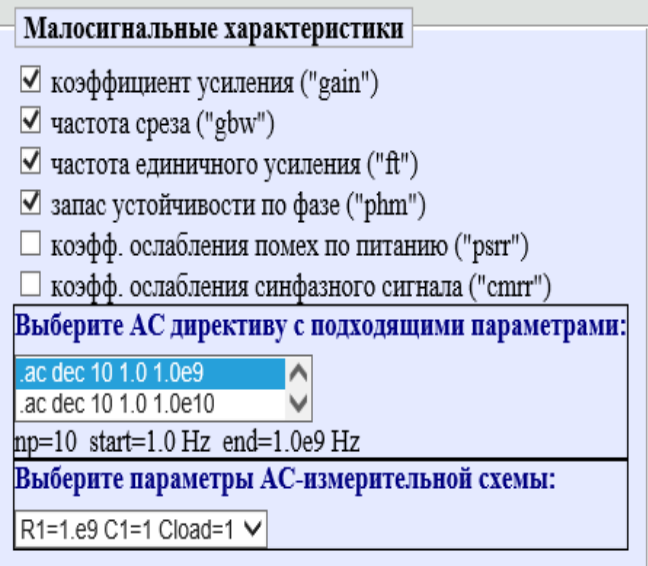

Параметры статики

$\square$ скорость нараст. Uвых ("slewrate") $\square$ ток потребления в статич. режиме ("isup")

Fig. 3. Specifying a list of calculated indicators

The user is provided with a list of all elements available for use in this circuit, from which he chooses the ones he needs.

All indicators are calculated automatically, the user can, within certain limits, influence the measurement circuit of the indicator.

To calculate the output parameters ordered by the user, several elements are automatically added to the main circuit. These extra elements are signal sources and components, allowing the main circuit to be switched to the required mode of operation and to prepare the elements to be measured.

At present, the system has one circuit for the parameters of a large signal (fig. 4) and three types of test circuits for measuring small signal characteristics (fig. 5). The current consumption is calculated in static mode.

All test circuits are created automatically "on the fly". The user cannot change the structure of tests on the circuit, but can change the parameters of extra elements.

\section{Circuit for signal slew rate measurement}

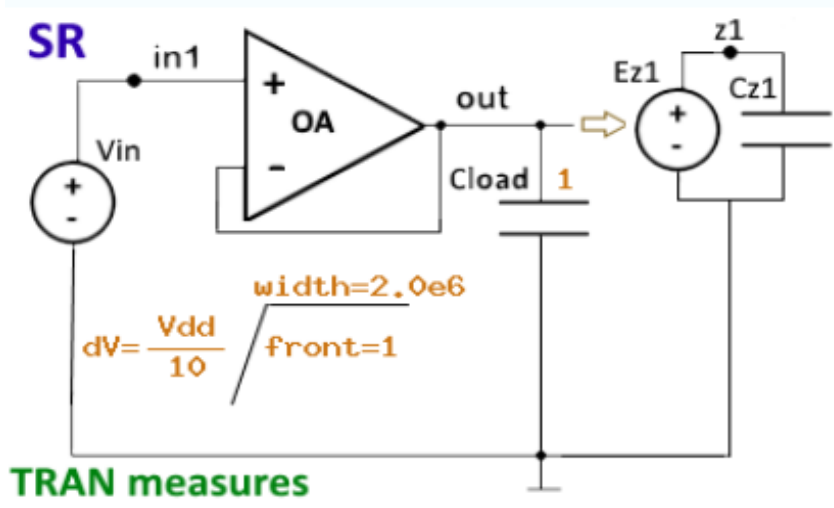

Parameters of circuit components (2 records)

\begin{tabular}{|c|c|c|}
\hline \multicolumn{3}{|c|}{$\begin{array}{l}\text { sweep }=10 \text { front }=1 \text { width }=2.0 \mathrm{e} 6 \text { Cload }=1 \\
\text { sweep }=10 \text { front }=1 \text { width }=2000000 \text { Cload }=1000\end{array}$} \\
\hline sweep: 10 & $\%$ of Vdd & \\
\hline front: 1 & ns & \\
\hline width: $2.0 \mathrm{e} 6$ & ns & Save \\
\hline Cload: 1 & $\mathrm{pF}$ & \\
\hline
\end{tabular}

\section{Parameters of transient analysis (2 records) tr $1.0 \mathrm{e}-91.0 \mathrm{e}-6$ \\ tr $1.0 \mathrm{e}-91.0 \mathrm{e}-5$ \\ step of analysis: \\ end time of analysis:

\begin{tabular}{|c|}
\hline $1.0 \mathrm{e}-9$ \\
\hline $1.0 \mathrm{e}-6$ \\
\hline
\end{tabular}

Fig. 4. Test circuit for calculating the rate of increase of the signal 


\section{Frequency analysis command options}

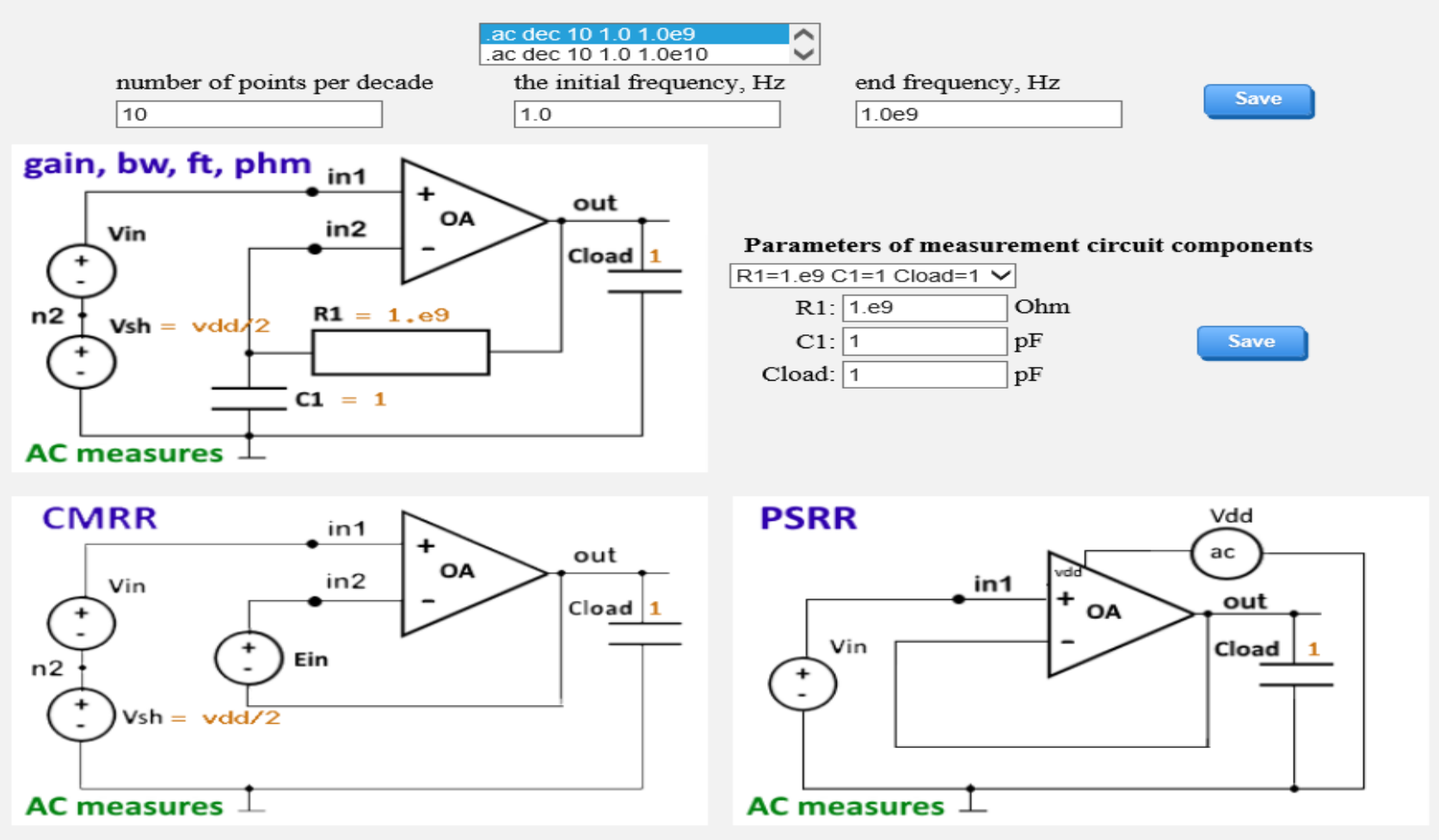

Fig. 5. Test circuits for calculating low signal characteristics

\section{CHARACTERIZATION MODES}

We have already mentioned that the system ARS has several types of characterization, which can be divided into two groups (fig. 6):

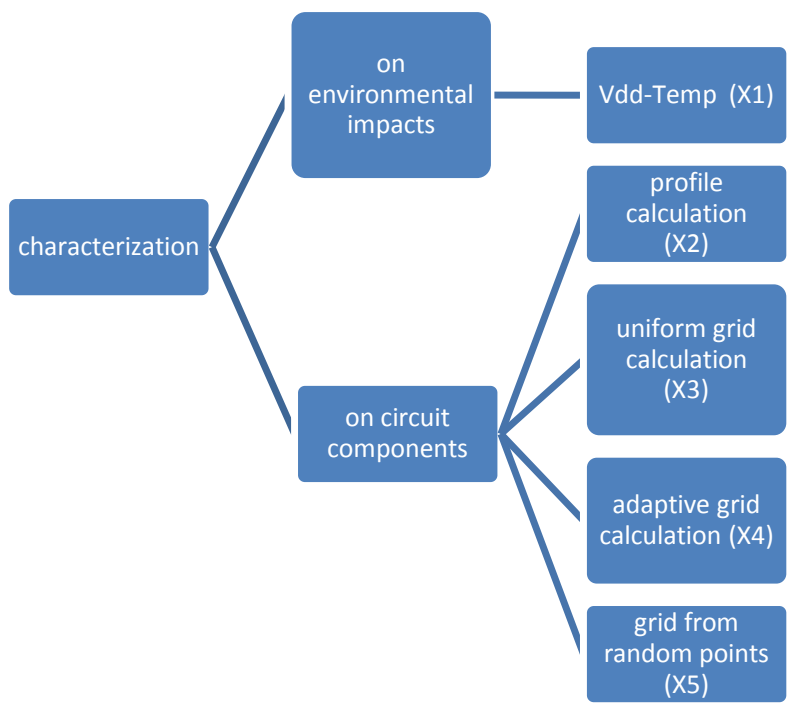

Fig. 6. Types of characterization in ARS

- X1: calculation of circuit parameters in the “corner” and central point of $\mathrm{V}-\mathrm{T}$ space $(« \mathrm{~V} »$ is $\mathrm{Vdd}$, supply voltage; $\mathrm{T}$ is analysis temperature).

- X2: calculation of "profiles" (dependencies of output indicators on one variable parameter).
- X3: calculation of circuit indicators on the grid of variable parameters. The grid spacing is uniform or logarithmic. The number of parameters is unlimited.

- X4: calculation of circuit performance on an adaptive grid, the nodes of which are selected on the basis of a given accuracy of calculations.

- X5: calculation of the parameters of the circuit in the grid randomly selected nodes.

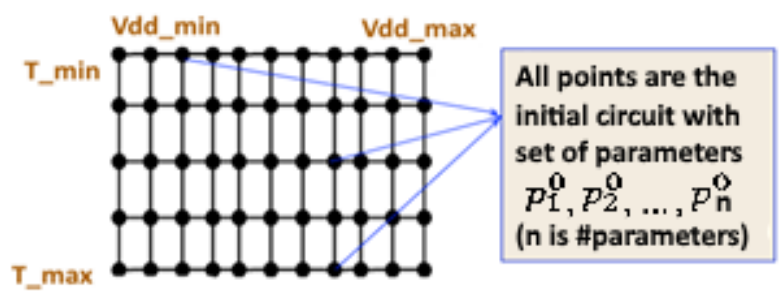

Fig. 7. The choice of points in characterization by external influences

Such set of grids is determined by searching for a compromise between processing time and accuracy of creation of hyperplane on grid. If it is supposed to get a grid with a small number of points (few changing variables and few points for each of them), it is more convenient to use the calculation on a uniform grid. Otherwise, you can try to obtain the desired estimate on the adaptive grid or grid, the nodes of which are chosen randomly. Because of each variable parameter is always obligatorily discretized (i.e. minimum grid step is greater 
than zero), then it is understand that in the ultimate case these two grids also become uniform.

Further we give a brief look at above-mentioned procedures of grid selection.
The system of selecting points for the $\mathrm{X} 1$ procedure is shown in fig. 7. This is a simple rectangular grid with uniform (or almost uniform in the case of temperature) step.

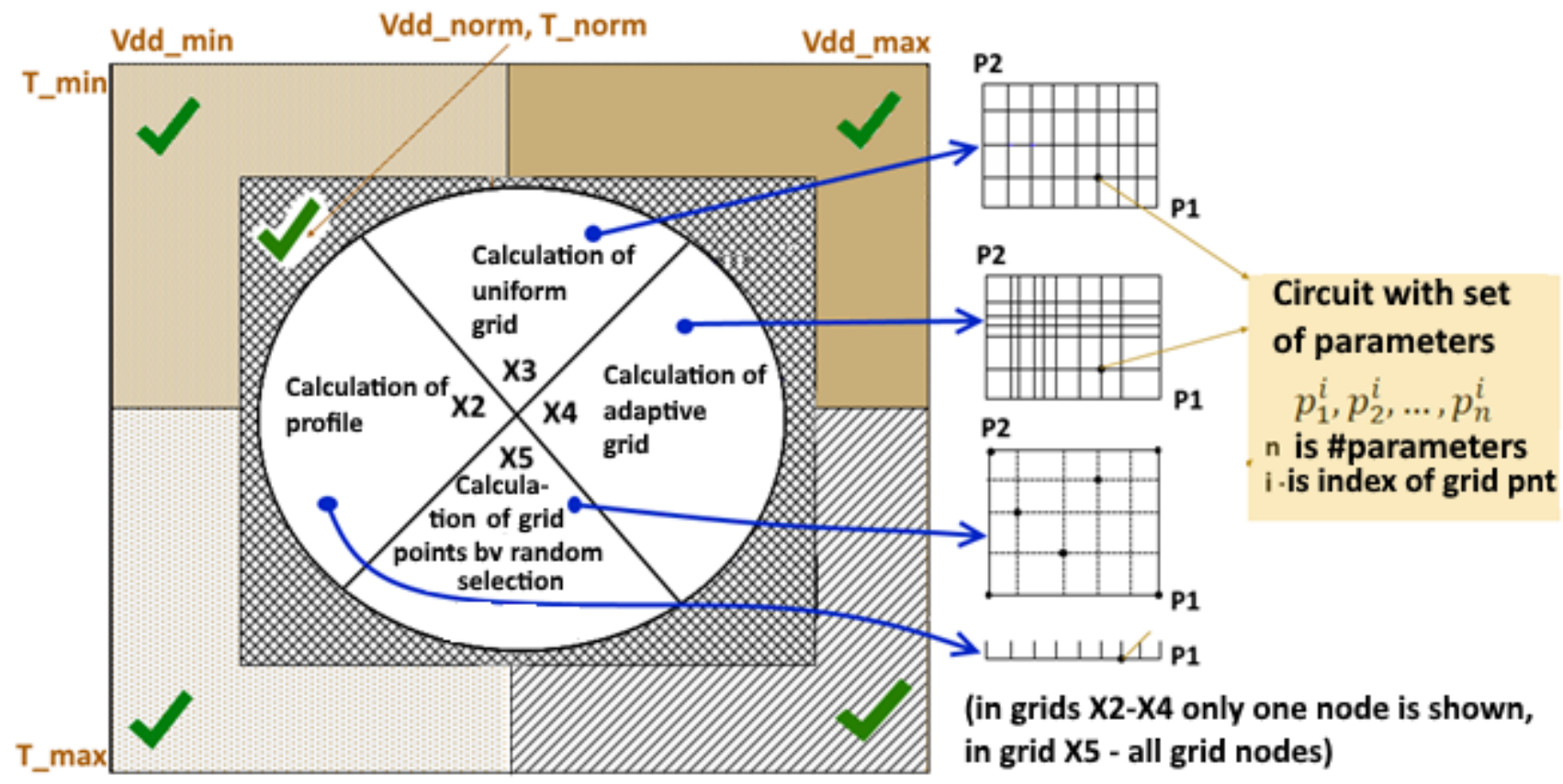

Fig. 8. The ratio of procedures and the choice of points for characterization by circuit components

The relationship between a task selection algorithms and system for selecting points for procedures X2-X5 better may be represented as a three-layer object (Fig. 8). The outer layer (with green check marks) is the ability to set from 1 to 5 points in Vdd-Temp space (by default only the center point is used). The middle layer (four sectors in a circle) is the choice of the type of the characterization process: for $n$-variables building $a$ uniform, adaptive or random grid, or building a profile for one variable. The inner layer is the calculations in all nodes of the selected grid at a given Vdd and temperature.

For a uniform grid and profile the user indicates the number of points for each variable and the type of the step change - linear or logarithmic. For adaptive grid the nodes are selected automatically based on the user-given accuracy. For a grid with a random choice of points the maximum running time of the algorithm is specified.

\section{VISUALIZATION OF RESULTS}

The result of the work of the characterization procedures is a set of points, each of which is a vector of modified circuit parameters and a corresponding vector of circuit parameters at this point. The user receive the results in the form of tables (fig. 9), one- (fig. 10) and two-dimensional graphs (fig. 11).

\begin{tabular}{|c|c|c|c|c|c|}
\hline N & M1_w & M2_w & gain, dB & phm, deg. & isup, MA \\
\hline 1 & 20000 & 20000 & 20.1415 & 85.442 & 0.00229817 \\
\hline 2 & 20000 & 25000 & 23.825 & 80.5358 & 0.00240819 \\
\hline 3 & 20000 & 30000 & 53.4393 & 50.1043 & 0.00249935 \\
\hline 4 & 20000 & 35000 & 38.6059 & 64.4679 & 0.00250252 \\
\hline 5 & 20000 & 40000 & 37.2038 & 65.097 & 0.00250369 \\
\hline 6 & 25000 & 20000 & 20.1508 & 85.0819 & 0.00229846 \\
\hline 7 & 25000 & 25000 & 23.8567 & 80.0887 & 0.00240862 \\
\hline 8 & 25000 & 30000 & 75.6107 & 45.0713 & 0.00249993 \\
\hline 9 & 25000 & 35000 & 38.6102 & 65.4938 & 0.00250253 \\
\hline 10 & 25000 & 40000 & 37.2107 & 66.1732 & 0.00250371 \\
\hline 11 & 30000 & 20000 & 20.1578 & 84.7867 & 0.00229868 \\
\hline
\end{tabular}

Fig. 9. Presentation of results in a table

\section{ClOUd TECHNOLOGIES}

The important feature of the system is that it is implemented on the basis of the cloud [5, 6 -8].

The vast majority of circuit simulation systems (the core of this system is the circuit simulation program usually) has one of two access modes: either it is a classic version of calling the system executable module, or Windows or a Linux command shell is called that translates commands of own menu into the corresponding exe-module directives. In any case such system is available either on the local computer or within the corporate network. 

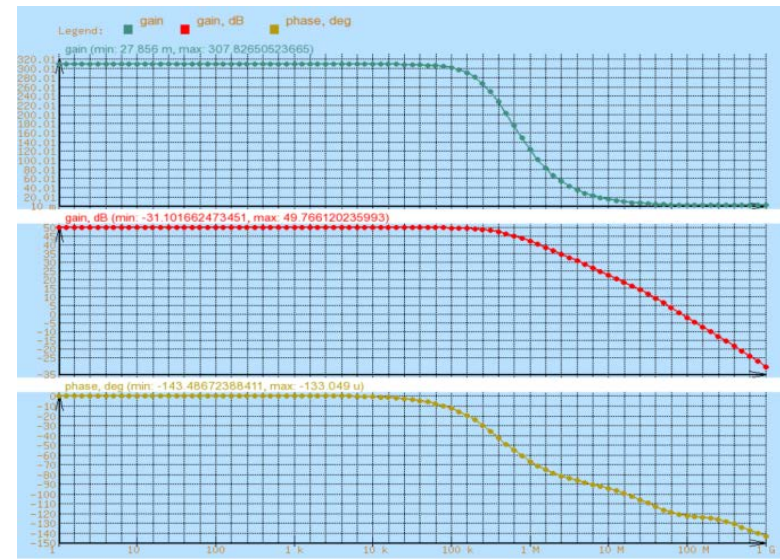

Fig. 10. Presentation of results as a graph

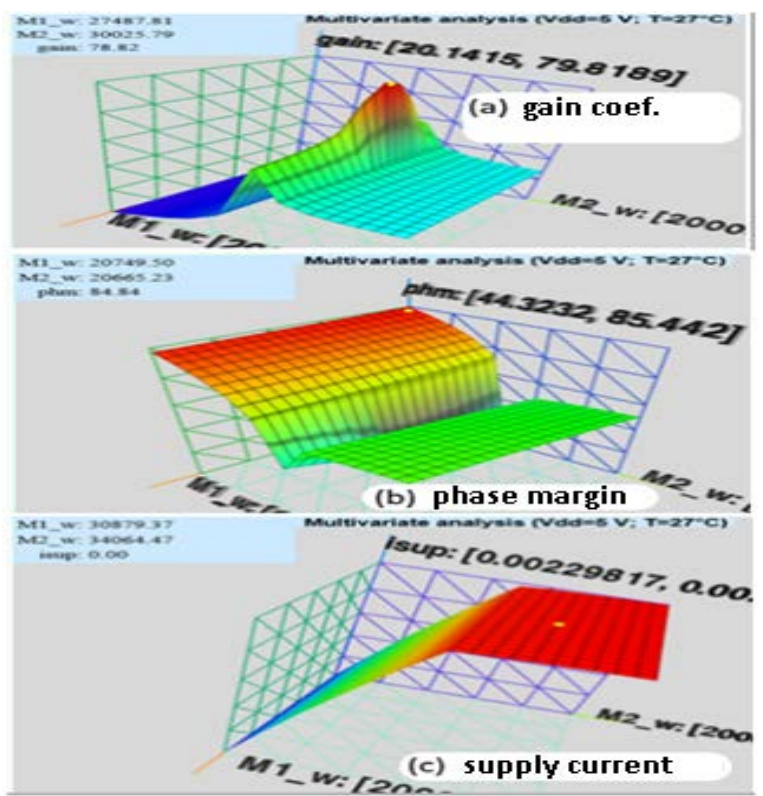

Fig. 11. Presentation of results in the form of 3Dgraphics (the yellow point on the surface is the measurement point, the measurement results in the upper left corner)

The ARS system is implemented in such a way that it is accessed from anywhere on the Internet. There is an input interface in the form of a conventional website. Work results are also shown on web pages. Starting the command of calculation of any characterization procedure, you begin the process of calculating several hundreds or thousands of variants of the same circuit on a dedicated computer. The advantages of this approach are obvious - firstly, the user does not need to install a circuit simulation program on his local network; secondly, he/she is released from routine work on the preparation of scripts for characterization of the existing circuit

\section{CONCLUSIONS}

Using for circuit analyses Spice-simulation programs in the "pure" form with the manual preparation of the initial data is quite time-consuming procedures. Known shells in wide-spread design systems (e.g., Virtuoso in Cadence [12]) are additional construction to facilitate the process of preparing the source data (e.g., via a graphical input) and display the results in graphical form.

The system considered in this paper, in contrast to the above-mentioned shells, prepares the task not for one calculation of the circuit, but for a whole set of points, allowing to evaluate the performance of the circuit using a variety of parameters. In addition, its implementation is based on cloud technology and provides a simple and convenient for most today users the call of system available on th from any Internet access point.

\section{REFERENCES}

[1] Synopsis standard cells library: https://www.synopsys.com/dw/ipdir.php?ds=dwc_standard _cell ( last accessed : 02/08/2018).

[2] A.L. Stempkovskij, S.V. Gavrilov, A.L. Glebov. Metody logicheskogo i logiko-vremennogo analiza cifrovyh KMOP SBIS // Rossijskaya Akademiya nauk, Institut problem proektirovaniya $\mathrm{v}$ mikroehlektronike, pod obshch. red. A.L. Stempkovskogo. Moskva, 2007. 224 p.

[3] Gavrilov S.V., Gudkova O.N., Egorov Yu.B. Metody uskorennoj harakterizacii bibliotek ehlementov SBIS s kontrolem zadannoj tochnosti. Izvestiya VUZov. EHlektronika. 2010. No. 3. S. 51-59.

[4] John Wright. Standard Cell Libraries for Mixed Signal Circuits. 2000.2 URL: https://www.eetimes.com/document.asp?doc_id=1224818 ( last accessed : 02/08/2018).

[5] Opredelenie oblachnyh vychislenij v NIST. URL: https://csrc.nist.gov/publications/detail/sp/800-145/final last accessed 13.11.17).

[6] Lyalinskij A.A. Osobennosti postroeniya prikladnyh programm web-dostupom. Informatika, №1 (37), JanuaryMarch 2013, s.76-83. Minsk. OIPI NAN Belarus. 2013

[7] Lyalinskij A.A. Avtomatizirovannoe formirovanie testov pri harakterizacii cifrovyh yacheek s ispol'zovaniem webdostupa. Problemy razrabotki perspektivnyh micro-i nanoehlektronnyh sistem. 2012. S. 95-100.

[8] Lyalinsky A.A. Web-based Digital Generation Systems // Problems of Perspective Micro- and Nanoelectronic Systems Development - 2012. P. 95-100.

[9] Gavrilov S.V., Gudkova O.N., Pirutina G.A., Gates and Devices Analysis . 2012. P. 119-124.

[10] CCS delay model.

URL: http://www.paripath.com/blog/characterizationblog/comparing-nldm-and-ccs-delay-models (last accessed 3/14/18).

[11] ECSM delay model. URL: https://projects.si2.org/events_dir/2006/oaconfspring2006/c adenceecsm.pdf. (last accessed 03/14/18).

[12] https://www.cadence.com/content/cadencewww/global/en_US/home/tools/custom-ic-analog-rfdesign/circuit-design/virtuoso-ade-product-suite.html (last accessed 03/15/18). 